\title{
Como a Antropologia pode contribuir para a pesquisa jurídica? Um desafio metodológico
}

How can anthropology contribute to legal research in Brazil? A methodological challenge

Roberto Kant de Lima e Bárbara Gomes Lupetti Baptista

\section{(2) OpenEdition}

Edição electrónica

URL: http://journals.openedition.org/aa/618

DOI: $10.4000 /$ aa. 618

ISSN: 2357-738X

\section{Editora}

Programa de Pós-Graduação em Antropologia Social (UnB)

Edição impressa

Data de publição: 1 junho 2014

Paginação: 9-37

ISSN: 0102-4302

\section{Refêrencia eletrónica}

Roberto Kant de Lima e Bárbara Gomes Lupetti Baptista, «Como a Antropologia pode contribuir para a pesquisa jurídica? Um desafio metodológico», Anuário Antropológico [Online], v.39 n.1 | 2014, posto online no dia 01 outubro 2014, consultado o 27 abril 2021. URL: http://journals.openedition.org/aa/ 618 ; DOI: https://doi.org/10.4000/aa.618

Este documento foi criado de forma automática no dia 27 abril 2021.

\section{cc) (†)}

Anuário Antropológico is licensed under a Creative Commons Atribuição-Uso Não-Comercial-Proibição de realização de Obras Derivadas 4.0 International. 


\section{Como a Antropologia pode contribuir para a pesquisa jurídica? Um desafio metodológico}

How can anthropology contribute to legal research in Brazil? A methodological challenge

Roberto Kant de Lima e Bárbara Gomes Lupetti Baptista

\section{NOTA DO EDITOR}

Recebido em: 16/09/2013

Aceito em: 18/11/2013

\section{Entre o Direito e a Antropologia: uma proposta empírica de aproximação destes saberes}

1 Antes de tratarmos diretamente do assunto a que nos propusemos, entendemos que seria relevante destacar aquilo que consideramos o aspecto crucial que norteia não apenas este trabalho, mas todas as demais produções acadêmicas que vêm sendo realizadas por um de nós, Roberto Kant de Lima, ou sob sua orientação, e pelos nossos parceiros em muitos espaços institucionais de produção do conhecimento e, notadamente, no INCT-InEAC, Instituto de Estudos Comparados em Administração Institucional de Conflitos (www.uff.br/ineac) ao qual pertencemos, qual seja: o reconhecimento da relevância da realização de pesquisas empíricas, que envolvam trabalho de campo, de caráter etnográfico e comparativo, para a compreensão do Direito e de suas instituições.

2 A importância de articular Direito e Antropologia - embora reconhecida por instituições como o MEC, que inseriu a Antropologia Jurídica no currículo da graduação em Direito, 
e pelo CNPq, que a elenca como subárea do Direito - ainda não está de fato legitimada pelos operadores jurídicos.

3 O fazer antropológico pressupõe a relativização de verdades consagradas, enquanto o fazer jurídico através delas se reproduz, sendo este contraste metodológico um significativo obstáculo ao diálogo destes campos. Exercitar a aproximação destes saberes é um desafio não apenas para o Direito, mas também para a Antropologia, pois ambas as áreas não pautam as suas agendas a partir de discussões comuns.

4 No entanto, a proposta deste artigo é precisamente destacar a importância de uma metodologia própria da antropologia, a etnografia, de base empírica e calcada no trabalho de campo e no método comparativo contrastivo, para o desenvolvimento da pesquisa na área do Direito. ${ }^{1}$ Para tanto, pretendemos não só demonstrar que o trabalho de campo e a etnografia são uma metodologia extremamente valiosa para o estudo e para a compreensão do campo jurídico, como também explicitar alguns dos obstáculos que causam os ruídos de comunicação destes campos. 0 contraste do Direito, afeito a respostas prontas e padronizadas, com a Antropologia, acostumada com perguntas e relativizações, traz resultados interessantes para a interdisciplinaridade, tão valorizada na produção do conhecimento científico contemporâneo.

5 Nesse sentido, este artigo pretende, para além de destacar a necessidade de aproximação destes diferentes saberes, o do Direito e o da Antropologia, chamar a atenção para o fato de que esta aproximação dificilmente terá êxito se for imposta exclusivamente por via teórica, pois as teorias antropológicas, por si sós, não parecem atrativas aos operadores do campo do Direito. Entretanto, poderá ser muito valiosa, como de fato vêm demonstrando os resultados de pesquisas que temos produzido institucionalmente, se for feita por via metodológica, através da realização de etnografias comparativas e contrastivas, com as quais os juristas não têm afinidade e sentem muita dificuldade de atribuir-lhes o devido valor.

6 Propor esse exercício de aproximação no espaço de uma Revista tradicional na área das Ciências Sociais assume especial relevância, pois a articulação entre o Direito e a Antropologia, embora extremamente profícua, como se pretende demonstrar neste trabalho, ${ }^{2}$ não é propriamente uma tradição no campo jurídico. Ao contrário, foi - e ainda é - bastante refutada em certos espaços de produção, legitimação e consagração do saber, o que torna a sua integração um grande desafio, como sugere o título do artigo.

7 O olhar antropológico é essencialmente um olhar marcado pelo estranhamento, mas não no sentido de suspeição. Trata-se, na verdade, de uma forma peculiar de ver o mundo e as suas representações, partindo sempre, necessariamente, de um surpreender-se com tudo aquilo que aos olhos dos outros parece natural. Relativizar categorias e conceitos e desconstruir verdades consagradas são, pois, importantes exercícios antropológicos e podem ser igualmente um fundamental exercício jurídico, de grande valia para promover as consequentes transformações pelas quais o Judiciário vem lutando e necessita concretizar, caracterizando-se também como um esforço significativo para se tentar romper com as formas tradicionais de produção, legitimação e consagração do saber jurídico.

8 A nossa contribuição com este trabalho caminha, portanto, no sentido de chamar a atenção para a necessidade de se começar a pensar o Direito a partir de outra 
perspectiva que não as que vêm sendo tradicionalmente utilizadas pelo campo dogmático.

9 E por quê? Porque o próprio campo jurídico começou a se dar conta de que as respostas prontas e definitivas que o Direito oferece para os problemas dinâmicos e cotidianos enfrentados pelo Judiciário não atendem às demandas diferenciadas da sociedade.

$\mathrm{E}$, além disso, esse notório descompasso, verificado entre aquilo que os cidadãos desejam e aquilo que a Justiça lhes oferece, está causando uma incontornável crise de (des)legitimidade desse Poder da República, que precisa resgatar a sua credibilidade para fazer cumprir o seu papel de administração institucional de conflitos, que é primordial para o fortalecimento do Estado Democrático de Direito, ainda muito distante da nossa realidade.

11 Realidade, a propósito, é uma palavra de ordem neste trabalho, pois a pesquisa empírica pressupõe justamente o direcionamento do olhar para o contexto fático. A pesquisa empírica não deixa de ser um instrumento que mensura a realidade. No caso do Direito, enquanto objeto de pesquisa, a análise das práticas judiciárias é a ferramenta metodológica que permite lançar um espelho autorreflexivo sobre o Judiciário e suas tradições e, a partir disso, ao conhecê-los melhor, tentar aprimorá-los, pois, com efeito, só é possível transformar aquilo que se conhece ${ }^{3}$ (DaMatta, 1987:48-50).

12 A possibilidade de iniciar um diálogo com as Ciências Sociais já ganha contornos institucionais no próprio campo do Direito, através, por exemplo, da introdução da disciplina denominada Noções Gerais de Direito e Formação Humanística como parte da prova eliminatória em concursos públicos para ingresso na carreira da magistratura em todos os ramos do Poder Judiciário nacional (Resolução $\mathrm{n}^{\circ} 75$, de 12 de maio de 2009). $\mathrm{E}$ também pela atuação da ENFAM - Escola Nacional de Formação e Aperfeiçoamento de Magistrados, que funciona junto ao Superior Tribunal de Justiça (STJ), e que pretende desenvolver, em parceria com a academia, ${ }^{4}$ pesquisas voltadas para uma melhor compreensão da aplicação prática do Direito. Sobreleva-se, neste caso, a recente publicização de um edital, elaborado pelo Conselho Nacional de Justiça em parceria com a CAPES, intitulado CNJ Acadêmico ${ }^{5}$ - Programa de apoio à pesquisa jurídica, visando justamente estimular o profícuo diálogo a ser estabelecido entre a academia, instância de produção do conhecimento científico, e o Judiciário, até então normalmente estudado e pesquisado interna corporis. São todas, pois, estratégias ou políticas institucionais que parecem apontar para uma nova direção do campo jurídico, tanto na esfera do saber (acadêmico) quanto na esfera do poder (Judiciário).

No entanto, é certo que, apesar de isolados esforços, em termos de pesquisa, muito pouco se caminhou no campo do Direito, que permanece ainda bastante atrelado a dogmas e tradições que não se compatibilizam com as referências acadêmicas da sociedade contemporânea.

Justamente devido à carência de pesquisas de caráter empírico na área do Direito é que entendemos que a contribuição da antropologia deve-se dar pela via metodológica da empiria e da comparação, e não de outro modo. Entretanto, é preciso de início esclarecer que a pesquisa empírica é um desafio significativo para o campo do Direito, seja porque os seus operadores não estão socializados com essa metodologia, seja porque estão acostumados a pensar o Direito a partir de ideais abstrato-normativos (dever-ser) que costumam obscurecer a visão do campo para práticas e rituais que os contrariam, que se tornam objeto de estigma e, no limite, de denúncia, acusação e criminalização, não de pesquisa. Além do fato de que, socializados na lógica do 
contraditório, da disputatio, seja no processo, seja na produção da dogmática, os juristas são muito pouco afeitos à lógica da argumentação, voltada para consensualizações provisórias e sucessivas.

15 Nesse sentido, a empiria, que só pode ser constituída, validada e estruturada sob consenso, não ganha legitimidade no campo como método de produção de conhecimento: é como se, fundada no consenso, não existisse, pois na disputatio só o dissenso existe (Berman, 2006:163-167). A construção do conhecimento jurídico, em sua quase totalidade, segue princípios enraizados na disputatio escolástica medieval e que são análogos àqueles utilizados para produzir a verdade judiciária na civil law tradition, ancorados nas fórmulas adequadas ao exercício da lógica do contraditório. ${ }^{6}$ Esta, como se sabe, funda-se no oferecimento obrigatório de dissensos infinitos à autoridade de terceiros, que optarão por uma das versões para fazê-la vencedora, sem considerar a conveniência das partes. No processo em busca de UMA verdade, dá-se mais relevância, para descobri-la, à lógica dos argumentos de autoridade do que àquela da autoridade dos argumentos, esta última própria da argumentação científica contemporânea, fundada na construção dialógica e sucessiva de consensos temporários, fundamento de seu suporte fático.

Observe-se também que não se deve confundir o método de construção da verdade jurídica, denominado de adversário - em inglês, adversarial - porque implica a participação de duas partes (Hall, 2009:284-286), distinguindo-se assim daquele que constrói a verdade jurídica de maneira monológica e autoritária, como é o caso das inquirições-devassas (Lima, 2008, 2008a, 2008b, 2010). No caso adversário, as partes estão inicialmente divergindo, mas podem concordar a qualquer momento desse processo para chegarem a um acordo sobre a verdade construída que a todos satisfaça. Não é o caso da forma do contraditório que toma esse método adversário, a qual vige em nosso sistema judiciário e que se ensina também como método produtor da Ciência do Direito: neste caso, as partes estão obrigadas a divergir, deixando sempre a uma autoridade externa a elas a decisão da descoberta da verdade. ${ }^{7}$

Por isso, a prática da pesquisa empírica como método de construção do conhecimento é um instrumento que nos parece eficaz para a (re)construção de um Judiciário mais democrático, entendendo-se a ideia de democracia, neste contexto, como o caminho ou o espaço necessário de interlocução e de aproximação entre as partes, no caso o Tribunal e a sociedade, nas formas de administração institucional de seus conflitos. Aliás, os Tribunais Superiores, através de discursos de seus presidentes, ${ }^{8}$ têm demonstrado de forma recorrente um interesse efetivo em promover esse contacto entre cidadãos e Tribunais, a fim de minimizar os efeitos da falta de legitimação pela qual o Judiciário está passando.

\section{A resistência do Direito à pesquisa empírica: um dos dilemas da aproximação com a Antropologia}

Os discursos produzidos pela dogmática - baseados essencialmente em opiniões, em vez de dados, ou evidências - ainda sustentam a produção "teórica" do Direito, embora não encontrem qualquer correspondência empírica. Isto tem como consequência o fato de que ler leis, livros e manuais de Direito não é suficiente para construir uma percepção 
adequada do campo jurídico e tampouco permite entender a lógica do nosso sistema judiciário.

19 Assim, é somente a partir da conjugação dos diversos tipos de saberes produzidos no campo do Direito (teóricos e empíricos) que se poderá tentar entendê-lo melhor e, com isso, eventualmente, aprimorar os seus mecanismos para torná-lo mais transparente. Nesse sentido, como já mencionado, assume importância o estudo das práticas judiciárias, normalmente relegado pelos juristas, mais preocupados em manualizar o conhecimento jurídico, uniformizando as suas categorias e normatizando condutas segundo um conceito idealizado e utópico.

20 Sobre este aspecto, da manualização do conhecimento jurídico, a leitura de Kuhn (2009:175-183) ajuda a compreender que esta forma de lidar com o saber torna-o insusceptível de provocar uma revolução científica - capaz de permitir uma ruptura com dogmas consagrados embotadores do conhecimento novo e criativo - além do que obscurece a compreensão mais global dos fenômenos jurídicos, pois as "teses" que chegam aos manuais, em geral, são as teses vencedoras dessa disputa acirrada do campo pelo monopólio de dizer o Direito (Lima, 2010), logo excludentes e não representativas de consensos, que, apesar de necessariamente provisórios, ilustram as problemáticas obrigatórias do campo científico em um determinado momento. ${ }^{9}$

21 Ao contrário da construção dogmática do Direito, ${ }^{10} \mathrm{o}$ estudo das práticas judiciárias, realizado a partir de pesquisas etnográficas de caráter antropológico, permite uma interlocução com o campo empírico, que incorpora à produção do saber jurídico os significados que os operadores do campo atribuem à Lei e às normas, possibilitando uma percepção não apenas mais completa, como também mais democrática dos fenômenos e dos institutos jurídicos.

22 O trabalho de campo e especialmente a etnografia permitem perceber valores e ideologia diferentes daqueles que informam explicitamente os discursos oficiais do campo. No caso do Direito, é certo que o discurso teórico produzido no campo nem sempre encontra correspondência nas práticas judiciárias, e vice-versa. Isto se deve, segundo nos parece, não apenas ao fato de que existe uma notória incompatibilidade entre os rituais judiciários e os valores e a ideologia explicitados nos manuais e nos livros de doutrina, mas especialmente ao fato de que existe, para além disso, uma completa invisibilidade dos valores e da ideologia que norteiam os mesmos rituais. Nesse contexto, a pesquisa etnográfica surge exatamente para, através da descrição minuciosa e da recorrência dos dados de campo, amparada nas referências comparativas, tornar mais transparente tal "teoria" (valores e ideologia) que orienta as práticas e os rituais que se mostram incompatíveis com o discurso dogmático oficial (Lima, 2008:236).

23 Na pesquisa empírica, a voz dos operadores do campo e dos cidadãos é ouvida, e o objeto do estudo internaliza a concepção teórica produzida pelos juristas de forma articulada com o mundo prático, dos cartórios e dos tribunais, normalmente olvidado pelos teóricos do dever-ser. ${ }^{11}$

24 A pesquisa empírica, articulada através de trabalho de campo, é nada mais nada menos do que a possibilidade de vivenciar a materialização do Direito, deixando de lado, por um momento, o referencial dos códigos e das Leis para explicitar e tentar entender o que de fato acontece e - no caso do Direito - o que os operadores do campo e os 
cidadãos observados dizem que fazem, sentem e veem acontecer todos os dias enquanto os conflitos estão sendo administrados pelos Tribunais. ${ }^{12}$

Isto é importante porque, embora o mundo jurídico seja estabelecido e legitimado internamente como uma esfera à parte das relações sociais, o fato é que, na realidade, $o$ Direito não pode ser estudado de forma dissociada do seu campo social de atuação porque ele é parte integrante desse espaço, constituindo-se no aspecto normativo de cada sociedade (Geertz, 1998). Em sendo assim, em nada contribui para sua compreensão essa autoimagem de um saber "monolítico" ou estritamente lógicoformal (Lima \& Varella, 2008; Fragale Filho, 2007). ${ }^{13}$

Apesar da relevância de se perceber o Direito a partir das suas manifestações práticas, é fato que o conhecimento advindo da empiria é desvalorizado no campo jurídico que, como dito acima, por ser instituído como um sistema normativo abstrato e idealizado, em detrimento dos fatos, insiste na busca desses tais ideais, muitas vezes inatingíveis, de tão distantes da realidade. Devido a tudo isso, o Direito acaba por resistir ao estudo das práticas, que são vistas como um conhecimento menos prestigioso, pois ou se presumem conforme sua idealização, ou se constata serem desviantes dela, caso em que se tornam um erro a ser corrigido e não um fato a ser estudado.

Para ilustrar a dificuldade que o campo jurídico tem de aceitar a "intervenção" de outros saberes em seu próprio universo, destacamos um trecho de uma entrevista concedida pelo ex-presidente do Superior Tribunal de Justiça, ministro Edson Vidigal, ao criticar o resultado de uma pesquisa empírica encomendada pelo Supremo Tribunal Federal, à época presidido pelo ministro Nelson Jobim, cuja conclusão foi no sentido de que no Brasil há juízes demais e o Judiciário gasta de modo exagerado. ${ }^{14}$ Disse o ministro: "[...] o que acontece é que no Brasil há muita tese de mestrado. E o pessoal gosta muito de elucubrar. Parece que essa pesquisa foi produto de acadêmico [...] Eu não sei de onde tiraram essa conclusão [...]".

Assim, o campo jurídico brasileiro, diferentemente de outros campos jurídicos ocidentais, tem uma dificuldade epistemológica de assimilar parâmetros acadêmicos fundamentados em pesquisa empírica e de considerar como saber qualificado aquele cujos dados têm essa origem (Lima, 2008b; Amorim et al., 2003; Amorim et al., 2005). Isto se deve, dentre outros fatores, não só aos obstáculos epistemológicos postos pela lógica do contraditório, já referidos, mas também ao desmesurado abismo existente entre o Direito escrito/legislado/normatizado e o Direito praticado. Aquele, idealizado. Este, preso aos muros circunscritos dos nossos Tribunais, acessado por poucos e conhecido por um pequeno grupo de pessoas: aqueles que atuam, pragmática e profissionalmente, nesse campo.

o conhecimento jurídico, fundado em versões consagradas e dogmas instituídos e míope ao olhar para a realidade, é então atualizado de forma a não produzir transformações, mas cópias autorizadas. Conhecer, nesse campo, equivale, na maioria das vezes, a deixar as coisas tal como estão e não intervir no seu modo de atuação. Trata-se de uma visão limitada do conhecimento que leva não só à estagnação do campo enquanto saber, mas especialmente à sua deslegitimidade enquanto Poder (Judiciário). o campo jurídico não se permite ser descrito ou analisado de forma diferente, assim como não quer ter de incorporar em sua estrutura as suas descrições. Com isso, acaba ficando sempre igual. E, neste artigo, é esta a questão que mais nos interessa destacar (Lima \& Varella, 2008). 

reproduz de forma ideal. Até porque a sua descrição empírica nunca equivalerá à sua idealização abstrata, e este campo, como já dito, prefere ignorar e/ou descartar os fatos, sob pena de rejeitá-los todos por não corresponderem às suas projeções idealizadas. Ao fazer isso, como num passe de mágica, o campo se torna ideal, pois ele próprio obscurece os problemas e as dificuldades do mundo empírico, tornando-as invisíveis, logo, aparentemente, e para todos os efeitos lógicos, inexistentes. Em outra oportunidade, em texto produzido em parceria com o filósofo Alex Varella, chamamos essa postura do campo de "uma concepção transcendental do Direito", que permite a aceitação incondicional do dogma jurídico no qual o Direito seria definido como um campo descontextualizado dos demais, internalizando uma lógica um tanto metafísica para um saber com tão fortes pretensões normativas da empiria (Lima \& Varella, 2008:90).

32 Assim, as versões consagradas e autorizadas do campo ${ }^{15}$ são o cimento da formação jurídica, sempre limitada e restrita aos dogmas já postos, insensíveis à dúvida ou ao questionamento. Os "produtores de conhecimento jurídico" sequer são donos de seu próprio discurso, sendo o uso recorrente dos pronomes em terceira pessoa, em vez de em primeira, um dado bastante significativo dessa impropriedade intelectual do campo, que resvala numa ausência de reconhecimento da subjetividade desse poder-saber.

o Direito se constitui, portanto, a partir de autorreprodução e, mesmo quando alguém do campo escreve algo considerado criativo, ainda assim parte de limites já fixados pela consagração tradicional. Aproprio-me, mais uma vez, de uma reflexão de outrora (Lima, 1997:37), que se insere perfeitamente nesse contexto: "é um pouco como se as versões consagradas fossem a matéria-prima sobre a qual se edifica a atividade intelectual, que se limita a 'avançar' a partir daí, sem contestar seus próprios alicerces".

O professor Otávio Velho (1995:107), escrevendo sobre a necessidade de a Antropologia fazer um esforço autorreflexivo sobre o seu atuar, algo que se propõe neste texto em relação ao Direito, mencionou algo muito apropriado:

Na medida em que não fazemos isso [um esforço de autorreflexão para ficarmos conscientes de nossa própria posição], penso que a antropologia está correndo o risco de ficar muito satisfeita consigo mesma, acreditando que está ótima sem conseguir discutir mais profundamente o que está fazendo, por que está fazendo, quais são as condições institucionais em que está fazendo e quais as repercussões disso sobre o conhecimento [...] Acho que não devemos nos enganar com as nossas instituições, elas são devoradoras da criatividade [...] É preciso estar discutindo sobre o "real", e estar refletindo sobre aquilo que se está fazendo e que está fazendo parte desse real, está sendo incorporado permanentemente a ele (grifos nossos).

Refutar e obscurecer a empiria são formas de negar uma realidade incompatível com a idealização normativo-dogmática. 0 problema está no fato óbvio de que quanto mais se nega a realidade, mais se afasta a possibilidade de transformar o estado das coisas, pois quando se tenta mudar a partir de ideais abstrato-normativos, aumenta-se a probabilidade de insucesso e de ocorrência de efeitos não previstos. Por mais empenho que o Judiciário promova em tentar aproximar a sociedade dos Tribunais, de nada adiantará o esforço iniciado se ele não tomar consciência explícita de si próprio. Ouvir os cidadãos e os seus anseios e também aceitar descrever a sua própria realidade, tal como ela é, ${ }^{16}$ são medidas que permitem atuar de forma mais eficaz, ainda que a realidade refletida no espelho seja indesejável. 

(2008:117), mencionamos esta questão: "Seu fervor teorético implica confortavelmente dispensar o mundo, as especificidades e a diversidade empírica, para ficar com o espelho, que continuamente lhes devolve a imagem que desejam". o que se verifica é que a dogmática acaba por exercer esse papel de reproduzir simbolicamente imagens idealizadas, por mais que a realidade não se pareça com elas. Ao fazê-lo, obscurece, com uma cortina de fumaça, relações de hierarquia, de poder, de desigualdade que estão internalizadas na sociedade, queiram os juristas ou não. Mas, ao mesmo tempo, ao querer regular normativamente a empiria, sem reconhecê-la como parte do processo de normalização da sociedade, sujeita seu projeto normativizador a fracassos sucessivos, que acabam por transformar essa normatização em apenas um arremedo de controle, no qual campeia não a obediência voluntária própria das sociedades democráticas, mas o descaso com as normas, sempre por demais abstratas para regular seja o que for.

A contribuição que a Antropologia possibilita é fornecer bases metodológicas para que possamos trabalhar o Direito a partir de outra perspectiva: a empírica. É no campo da pesquisa jurídica que esse estranhamento do familiar e essa relativização dos conceitos ideais se mostram fundamentais para repensar o Direito e as suas formas de materialização.

Conhecer é intervir, é transformar, é tensionar, é problematizar, e isso o nosso Direito manualizado, dogmático, formalista e codificado não faz, e precisa aprender a fazer (Lima \& Varella, 2008). A esse propósito, Mannheim (1974:136) destaca em sua obra algo que se adéqua a essa ideia de que a manualização do ensino do Direito é, em grande parte, o eixo reprodutor, irrefletido e acrítico de produção do saber jurídico, que amortece o impulso crítico, imobilizando quem poderia pensar o Direito de uma forma diferente: "A comercialização miúda do conhecimento em pacotes padronizados paralisa o impulso para questionar e inquirir". Trata-se de uma lógica que paralisa o saber e funciona como uma camisa de força que aprisiona a produção desse conhecimento e, por conseguinte, restringe qualquer possibilidade de transformar antigos comportamentos em novas práticas.

Além disso, há outra questão fundamental a se considerar, já esboçada anteriormente: o Direito é um campo que não adota o consenso como categoria estruturante do conhecimento. Ao contrário, adota a lógica do contraditório como base e como forma de construção do seu saber, pois as "doutrinas" ou "correntes doutrinárias" nada mais são do que formas opostas de ver/interpretar o mesmo objeto, ao sabor da autoridade acadêmica ad hoc, muitas vezes confundida, pela analogia do método, com a autoridade judiciária. Por isso, este campo do conhecimento é dogmático e não científico.

Essa lógica do contraditório, que não se confunde com o princípio adversário, mas que nele encontra eco e inspiração, é internalizada e naturalizada pelos operadores que, por sua vez, reproduzem-na não apenas no processo judicial, mas também no processo de construção do saber jurídico.

41 Somado a isso, há ainda o fato de o Direito brasileiro se organizar e se constituir através de categorias não unívocas, cujo significado está sujeito à autoridade interpretativa ad hoc - logo, por definição, não sujeitas à interpretação literal, que é considerada ilegítima - possibilitando, assim, uma "luta interna" do campo para ver qual das possíveis interpretações das normas jurídicas terá a melhor aceitação. Nesse sentido, a consagração no interior desse campo do conhecimento exige uma concorrência pelo poder institucional, dotado de um saber particularizado, que lhe empresta legitimidade 
e que, por sua vez, distingue e hierarquiza os que alcançam o reconhecimento intelectual (os consagrados/autorizados) em face dos demais (Bourdieu, 1968, 1987). Quer dizer, nesse campo, saber é igual a poder (Lima, 2010).

Esta particularidade, inclusive, torna o Direito um tanto enigmático, já que as bases de sua legitimidade estão fincadas em um saber que não está disponível a todos e que, uma vez revelado - assim como se deu com Édipo ao desvendar o enigma da esfinge - leva imediatamente ao poder (Foucault, 2003). ${ }^{17}$

Um dado contundente e ilustrativo do que mencionamos, notadamente acerca da disputa pela legitimidade da produção do conhecimento jurídico, é o discurso de um ministro do STJ, reproduzido no seguinte trecho do seu voto vencido, datado de 2003:18

Sr. Presidente, li, com extremo agrado, o belíssimo texto em que o Sr. Ministro Francisco Peçanha Martins expõe as suas razões, mas tenho velha convicção de que o art. 557 veio em boa hora, data vênia de S. Exa. Não me importa o que pensam os doutrinadores. Enquanto for Ministro do Superior Tribunal de Justiça, assumo a autoridade da minha jurisdição. $O$ pensamento daqueles que não são Ministros deste Tribunal importa como orientação. A eles, porém, não me submeto. Interessa conhecer a doutrina de Barbosa Moreira ou Athos Carneiro. Decido, porém, conforme minha consciência. Precisamos estabelecer nossa autonomia intelectual, para que este Tribunal seja respeitado. É preciso consolidar o entendimento de que os Srs. Ministros Francisco Peçanha Martins e Humberto Gomes de Barros decidem assim, porque pensam assim. E o STJ decide assim, porque a maioria de seus integrantes pensa como esses Ministros. Esse é o pensamento do Superior Tribunal de Justiça, e a doutrina que se amolde a ele. É fundamental expressarmos o que somos. Ninguém nos dá lições. Não somos aprendizes de ninguém. Quando viemos para este Tribunal, corajosamente assumimos a declaração de que temos notável saber jurídico - uma imposição da Constituição Federal. Pode não ser verdade. Em relação a mim, certamente, não é, mas, para efeitos constitucionais, minha investidura obriga-me a pensar que assim seja. Peço vênia ao Sr. Ministro Francisco Peçanha Martins, porque ainda não me convenci dos argumentos de S. Exa. Muito obrigado (grifos nossos).

Esta forma de disputar a legitimidade sobre os significados e a extensão do conteúdo das normas jurídica é própria (e recorrente) do campo do Direito, destacando-se pronunciamento mais recente de ministro da Corte Especial do STJ, hoje no STF, que reverbera o discurso do ministro transcrito acima:

[...] o conteúdo da norma não é, necessariamente, aquele sugerido pela doutrina, ou pelos juristas ou advogados, e nem mesmo o que foi imaginado ou querido em seu processo de formação pelo legislador; o conteúdo da norma é aquele, e tão somente aquele, que o Poder Judiciário diz que é (Corte Especial, AI nos ERESP 644.736/PE, MIN. TEORI ALBINO ZAVASCKI, julgado em 06/06/2007).

O método do contraditório, enquanto forma de construção do saber jurídico, acaba por impedir consensos sucessivos e provisórios ao pressupor que existam teses certas ou erradas, justas ou injustas, a critério de uma autoridade institucionalmente constituída, estranha às partes, para situações da vida concreta, o que leva à falaciosa pretensão de estabelecer A verdade, que seria a "solução" do problema, em vez de internalizar a possibilidade de haver verdades possíveis construídas com base em consensos de “certezas provisórias" que contemplem todos os interesses e os interessados (Lima, 2008b:16). O estilo do Direito é a padronização pelo poder, não pelo saber, e o que não se amolda a esse formato é descartado. Com isso, a forma institucional de administrar conflitos nesse campo acaba produzindo desigualdades na aplicação da Lei, outro motivo que interfere na sua legitimidade. 
Ora, se o Direito refuta a empiria, a explicitação dos problemas, a descrição detalhada de suas práticas, a relativização ${ }^{19}$ e a desconstrução, dificilmente poderá vir a se constituir como um espaço dinâmico de autorreflexão científica, crítica e criativa que permita efetivar as mudanças necessárias pelas quais ele próprio clama.

\section{Sobre como o Direito pode incorporar o trabalho de campo e a etnografia: o princípio da oralidade processual}

Acreditamos que a descrição das práticas e dos rituais judiciários pode ser muito valiosa para a pesquisa no Direito.

As pesquisas empíricas têm a particularidade de permitir contrastar aspectos diferenciados do campo e das estruturas que o constituem e que não necessariamente se complementam, ao contrário, comumente se anulam. Exemplo disto é o que ocorre com o Princípio da Oralidade Processual, que na Doutrina e na Legislação assume um significado e, para os operadores do campo, outro, não apenas distinto, mas absolutamente contrário àquele.

Etnografia empreendida no Tribunal de Justiça do Rio de Janeiro acerca do Princípio da Oralidade Processual, utilizada neste artigo para ilustrar como o Direito pode incorporar a metodologia etnográfica em suas pesquisas, permitiu perceber que inexiste comunicação entre o mundo dos manuais de Direito e o mundo das práticas judiciárias, transitando este saber jurídico entre o real e o ideal, o que faz com que as suas lógicas sejam paradoxais e a sua compreensão, inexata: consequentemente, a sua atuação torna-se socialmente ilegítima (Lupetti Baptista, 2008).

50 A forma reprodutora através da qual o campo do Direito se manifesta impede - ou, pelo menos, restringe - a possibilidade de se enxergarem os aspectos implícitos que atuam nesse campo e que, queiram os juristas ou não, orientam a sua forma de atuar e regulam as suas práticas e rituais.

51 A etnografia possibilita exatamente que esses mecanismos, obscurecidos pela forma de produção e circulação do saber jurídico, se revelem e, tornando-os explícitos, permite uma melhor compreensão do campo e de sua lógica.

52 Especificamente em relação ao princípio da oralidade, analisando os rituais judiciários através da pesquisa de campo desenvolvida no Tribunal de Justiça do Rio de Janeiro, foi possível perceber que a dogmática atualiza o tema de uma forma absolutamente distinta daquela depreendida pela empiria.

53 A doutrina reconhece a oralidade como uma garantia das partes a um processo justo e democrático, portanto, um instituto fundamental que deve ser observado e assegurado a todos os cidadãos (Lupetti Baptista, 2008). No entanto, a análise dos rituais judiciários mostra que a oralidade é descartada pelos operadores do campo, sob o fundamento de que esta forma de manifestação processual acaba sendo um empecilho à concretização de outro princípio processual, ainda mais importante: o da celeridade da prestação jurisdicional.

54 A celeridade, assim como a oralidade, é um princípio de direito processual alçado à categoria de garantia, sendo que, diferentemente da oralidade, tem status constitucional, estando previsto expressamente no rol dos direitos e das garantias 
fundamentais dos cidadãos, a saber, no art. $5^{\circ}$, inciso LXXVIII, da Constituição da República. ${ }^{20}$

55 A finalidade precípua do princípio da celeridade, nos termos sustentados pela dogmática, é assegurar aos cidadãos a "duração razoável do processo", cujo significado, nas palavras de um processualista consagrado nesse campo, é assim traduzido: "o interesse público é o de que as demandas terminem o mais rapidamente possível, mas que também sejam suficientemente instruídas para que sejam decididas com acerto" (Santos, 1985:298).

Assim, o tempo tornou-se um fator significativo para a administração institucional de conflitos no Brasil, sendo a celeridade, modernamente, senão a maior, uma das mais importantes metas da agenda jurídica em pauta.

Nesse contexto, o que as práticas judiciárias apontam - e a dogmática desconsidera - é um nítido conflito entre princípios processuais, em que a oralidade cede espaço à celeridade já que, em sendo assegurados às partes todos os atos processuais orais legalmente previstos, a celeridade acabaria por não se efetivar e, no sistema vigente, a "duração razoável do processo" é um requisito essencial à prestação jurisdicional.

Curioso o que se verificou no trabalho de campo porque, ao se comparar o discurso dogmático com o empírico, notadamente acerca da dicotomia oralidade x celeridade, percebeu-se que, para o discurso teórico-dogmático, a oralidade tem uma conotação valorativa imensamente positiva. Ela é romanceada pelos doutrinadores, ao passo que no discurso dos operadores, que lidam com a oralidade em seu cotidiano, ela é, opostamente, vista com uma conotação negativa. É tida como algo que atrapalha o bom andamento do processo e que não tem destinação de fato útil.

59 A doutrina, como esperado - pois é assim que o Direito se estrutura: entre o real e o ideal - tem uma visão poética e utópica do princípio da oralidade no processo civil. Ao se lerem as manifestações dogmáticas, tem-se a sensação de que a oralidade é a solução de todos os males do sistema e o fim do abismo que notoriamente separa e distancia os cidadãos do Judiciário.

60 Ao ser categorizada como princípio norteador de um processo justo e democrático (Greco, 2005), a oralidade é reconhecida, no campo discursivo, como uma garantia de autodefesa da parte, proporcionada por um "diálogo humano e público com o juiz da causa" (Greco, 2005). A oralidade seria então o instrumento capaz de possibilitar ao juiz não só ouvir, mas especialmente "sentir" as partes e as testemunhas e, por conseguinte, avaliar melhor as provas diante dele produzidas e formar, com mais certeza e precisão, o seu convencimento.

61 A oralidade é representada na dogmática como um método que proporciona "à luta judiciária [o processo] o seu genuíno caráter humano, que comunica vida e eficácia ao processo [...]" (Morato, 1938); é um sistema em que o juiz participa ativamente do processo, entretanto, à sua autoridade pública sobrepõe-se a soberania individual das partes (Leal, 1938); trata-se de um mecanismo que possibilita "uma justiça rápida, perfeita e barata", sendo, na verdade, "um remédio heróico" (Cunha Barreto, 1938); é o que possibilita a palavra viva em sobreposição à escrita morta, eis que "na palavra viva fala também o vulto, os olhos, a cor, o movimento, o tom da voz, o modo de dizer, e tantas outras pequenas circunstâncias, que modificam e desenvolvem o sentido das palavras e subministram tantos indícios a favor ou contra a própria afirmação delas. A mímica, a eloquência do corpo são mais verídicas do que as palavras [...]" (Chiovenda, 
1938); a oralidade, afinal, "garante uma justiça intrinsecamente melhor; faz do juiz partícipe na causa e permite-lhe dominá-la melhor [...] assegura melhor a veridicidade e a sinceridade dos resultados da instrução [...]".

62 Percebe-se, portanto, uma alta carga de sensibilidade, nos juristas, ao estudarem e lecionarem sobre a aplicação desse princípio. Na prática, entretanto, nem sempre é assim que o processo se materializa, inclusive porque a escrita prevalece em função justamente da necessidade cada vez mais premente de celeridade na prestação jurisdicional (Lupetti Baptista, 2008).

Empiricamente, a oralidade é um obstáculo à celeridade processual e, não apenas por isso, mas especialmente, é vista como um entrave que inviabiliza a concretização do princípio constitucional que preconiza a "duração razoável do processo". Eis o que pensam os operadores.

A oralidade é a maior proximidade do juiz com a parte, com as testemunhas, tal, mas eu não acho que essa oralidade além do necessário seja benéfica. Muito pelo contrário, ela é muito maléfica. Tanto que estou em uma vara cível e posso afirmar que não há necessidade de se fazer mais do que dez ou doze audiências por mês. Não há. É inviável hoje em dia ficar ouvindo as partes, os advogados, não há tempo. Nós não temos mais tempo para essas questões. A oralidade atrapalha. Você não pode ser obrigado a fazer uma audiência (Juiz em exercício em Vara Cível da Comarca do Rio de Janeiro).

Nós temos regras que nós precisamos seguir [...] A oralidade, em Vara Cível, é muito mitigada porque ela faz com que o juiz gaste muito tempo ouvindo, ao passo que ele pode gastar menos tempo lendo (Juíza titular de Vara Cível da Comarca do Rio de Janeiro).

A oralidade atrapalha do ponto de vista prático. $\mathrm{O}$ volume de trabalho é muito grande. É muito mais rápido despachar por escrito, muito mais fácil analisar, ler as petições, do que ficar ouvindo as pessoas em audiência. Os advogados não têm poder de síntese, as partes muito menos. Não há condições de ouvir todo mundo ponderar o que quer. Temos que ser muito objetivos (Juiz titular de Vara Cível da Comarca do Rio de Janeiro).

Eu acho que, na prática, nem precisaria de oralidade [...] Tem tantas outras coisas que a gente pode fazer para diminuir o volume, para diminuir o tempo de processamento, sabe? [...] A prova oral não é muito útil. Você perde tempo, $1 \mathrm{~h}$ ou $1 \mathrm{~h}$ e meia e não vem a contribuição que você quer (Juíza de Vara Cível da Comarca do Rio de Janeiro).

Eu sei que há autores que defendem uma maior oralidade nos processos. Eu confesso a você que eu penso de forma diferente. Para mim, a oralidade é só nos casos estritamente necessários, porque a oralidade acaba sendo um entrave para o normal prosseguimento dos processos. Não vejo a oralidade como algo necessário. Aliás, acho que pode ser até prejudicial (Juiz titular de Vara Cível da Comarca do Rio de Janeiro).

Um juiz hoje não pode se dar ao luxo de ficar fazendo as audiências porque as partes querem, ou ouvir todo mundo porque as pessoas querem falar. Não pode. Não pode. Ele pode dar uma bela sentença escrita. Ele pode ser uma pessoa excepcional; dar uma bela decisão. Mas se ele não tem pulso, se ele deixa que coisas inúteis se produzam no processo, ele, no fundo, está prejudicando a distribuição da justiça (Juiz em exercício em Vara Cível da Comarca do Rio de Janeiro).

o contraste entre o discurso dogmático e os dados empíricos sugere que não apenas ambos representam a oralidade de forma absolutamente distinta, como também - o que nos pareceu mais interessante - o fazem de forma contraditória, já que a dogmática vê a oralidade como um instrumento a serviço da celeridade, e a prática judiciária, opostamente, a vê como um estorvo à celeridade. 


$$
\begin{aligned}
& \text { fulcral para a transparência do nosso sistema judiciário. A abertura do Direito, que, } \\
& \text { como dito, é um campo tradicionalmente hermético, é um importante passo para se } \\
& \text { alcançarem estratégias institucionais de mudança do quadro atual. }
\end{aligned}
$$

Marinoni e Arenhart (2005:671) assim se pronunciam sobre o tema:

A oralidade, sem dúvida, contribui não apenas para acelerar o ritmo do processo, como ainda para se obter uma resposta muito mais fiel à realidade. $O$ contato direto com os sujeitos do conflito, com a prova e com as nuances do caso permitem ao magistrado apreender de forma muito mais completa a realidade vivida, possibilitando-lhe adotar visão mais ampla da controvérsia e decidir de maneira mais adequada.

Os demais doutrinadores, acima citados, igualmente destacam a oralidade como a vantagem mais imediata do processo oral, especialmente por se considerar sempre menos penoso "ouvir do que ler". o processo oral, quando de sua implementação, foi visto como o remédio provadamente eficaz contra a lentidão do Judiciário. A oralidade foi recepcionada como o instrumento que libertou o processo de "fórmulas inúteis e arcaicas", destinando-se a tornar possível a solução dos litígios com economia de tempo (Gusmão, 1938; Estellita, 1938; Mendonça, 1938; Cunha Barreto, 1938; Oliveira, 1938).

No campo, todavia, como se pôde ver, a percepção que se tem do princípio da oralidade é reversa. Entende-se que o sistema oral é moroso e, atualmente, inviável.

O exemplo da pesquisa sobre a oralidade é ilustrativo, portanto, de que as incoerências e as desarticulações do sistema processual só são possíveis de ver se os rituais forem observados e, a partir daí, explicitados, descritos e postos sob análise. Sem isso, partindo de idealizações normativas que nenhuma correspondência têm com a empiria, o Direito continuará sendo um campo enigmático, hermético e incompreendido.

Desde 1983, no trabalho intitulado "Por uma Antropologia do Direito, no Brasil" (Lima, 2008:1-38), chama-se a atenção para a importância de se constituir um campo de pesquisa empírica, de base crítica, na área do Direito. Naquele texto, mencionava-se a necessidade de "se rasgarem os véus" do Judiciário e tornar explícitas as suas práticas para que fosse possível conhecer melhor esse saber e as atividades que o governam, sem que o acesso a esses dados fosse restrito aos membros internos e operadores do campo.

Passados mais de 30 anos, a dificuldade de se introduzir essa forma de pesquisa no Direito brasileiro permanece e, com isso, continua-se a retardar a constituição de um campo crítico-reflexivo sobre as práticas dos Tribunais.

Como fazer isso? Talvez, para além de difundir essa metodologia de pesquisar o Direito, fomentado-a no ensino da Graduação e da Pós-graduação, articular a relação institucional entre a academia e os Tribunais seja uma opção importante.

No entanto, para isso, seria necessário que os Tribunais, seus doutrinadores e operadores se permitissem pesquisar e serem pesquisados e se permitissem criticar e serem criticados academicamente, fora da lógica do contraditório. E quando manifestamos isto, não intentamos diminuir ou subjugar o poder-saber dos integrantes desse campo, mas, ao contrário, chamar a atenção para o fato de que a inculcação que neles se faz desde os bancos universitários acaba por formar operadores resistentes ao fazer jurídico diferente e treinados para a reprodução do conhecimento consagrado e dos dogmas que embotam a criatividade e a crítica. ${ }^{21}$ alcançarem estratégias institucionais de mudança do quadro atual. 
74 Por mais eventualmente indecorosa que seja a imagem refletida no espelho do Judiciário, a partir das pesquisas empíricas a serem realizadas, é preciso enfrentar, sem criminalizar nem estigmatizar, a descrição de suas práticas, pois é sua explicitação que permitirá aos operadores do campo ver aquilo que estão fazendo e, a partir dessa consciência, optar se querem continuar fazendo mais do mesmo ou se querem seguir na direção de novas perspectivas de atuação.

75 O autoconhecimento do Direito pelo Direito, através da interlocução com outros campos do saber, se faz premente, e a nossa proposta de pesquisa, acreditamos, vai ao encontro desse projeto comum, que visa, afinal, à construção do Judiciário de modo a afirmar o seu reconhecimento como um poder legitimamente democrático, republicano e acessível aos cidadãos.

\section{Algumas possíveis conclusões}

76 Além da pesquisa sobre a oralidade processual, ora objeto de análise e interpretação (Lupetti Baptista, 2008), diversas outras pesquisas empíricas estão publicadas e foram realizadas por pesquisadores formados em Direito (Moreira Leite, 2003; Ferreira, 2004, 2013; Figueira, 2005, 2008; Rocha Pinto, 2006; Silva, 2011; Mendes, 2012; Lupetti Baptista, 2013; Vidal, 2013) e que, portanto, fizeram o exercício antropológico de desconstruir e desnaturalizar as suas representações sobre o real, inculcadas durante a sua formação, para enveredarem-se por um novo caminho, de águas turbulentas, mas que, ao fim e ao cabo, permite entender o Direito a partir de outras concepções, o que possibilita uma contribuição única e bastante diferenciada para a reconstrução desse saber e, por conseguinte, para o aprimoramento do seu funcionamento. Isto, sem dúvida, colabora, como dissemos, para que se percebam os paradoxos do sistema judiciário e, com isso, se efetivem as necessárias rupturas nesse campo de poder que, como se sabe, clama por mudanças que o tornem mais democrático e legítimo.

Esses e outros resultados de pesquisas empíricas (Mota, 2005; Eilbaum, 2008, 2012) foram recentemente consagrados e institucionalizados na criação de nosso Instituto Nacional de Ciência e Tecnologia - Instituto de Estudos Comparados em Administração Institucional de Conflitos (INCT-InEAC), aprovado em fevereiro de 2009 pelo Ministério de Ciência, Tecnologia e Inovação através da iniciativa do Programa Institutos de Ciência e Tecnologia (Edital 15/08). O InEAC, hoje institucionalizado na UFF através da criação do Núcleo de Ensino, Pesquisa e Extensão em Administração Institucional de Conflitos, vinculado à Pró-Reitoria de Pesquisa, Pós-graduação e Inovação da UFF (NEPEAC/PROPPI/UFF), tem como proposta produzir pesquisas empíricas, em suas bases quantitativas e qualitativas, que permitam propor e avaliar políticas públicas, em nível federal, estadual e municipal, na área da Segurança Pública e do Acesso à Justiça, bem como desenvolver tecnologias de intervenção social nesses campos. O objetivo do Instituto é produzir e transmitir conhecimento empírico e teórico sobre as lógicas de tratamento e administração institucional de conflitos por parte dos agentes públicos, focalizando as suas pesquisas em etnografias, em uma perspectiva comparada, que direcionam o olhar para o mundo real.

Assim, o que propomos com este artigo é chamar a atenção para o fato de que a metodologia de pesquisa empírica, com base no trabalho de campo e eventualmente etnográfica e comparativa, é a melhor forma de identificar e diagnosticar os problemas e os obstáculos que impedem o bom funcionamento dessas instituições do país. 
79 Temos de reconhecer que, por enquanto, as pesquisas empíricas realizadas sobre as práticas e as instituições judiciárias são muito tímidas e restritas a poucos espaços institucionais de produção do conhecimento científico, mas já configura um bom começo o fato de que o Judiciário, através especialmente do CNJ, esteja promovendo parcerias oficiais com as agências de fomento, como a CAPES, para estimular estudos que direcionem um olhar externo de pesquisadores sobre o Judiciário.

Estudar o Direito, suas práticas, instituições e tradições, a partir de uma perspectiva empírica, é o que permitirá perceber, como inúmeras pesquisas já apontaram, que o Direito que se pratica está muito distante do Direito que se idealiza. Olhar para a realidade fática, construída de acordo com métodos das ciências humanas e sociais, vai possibilitar ver em que medida essa distância se verifica e, a partir disso, sem negar nem criminalizar as eventuais discrepâncias, engendrar, pelo contrário, o que é necessário fazer para alterar o rumo desses caminhos tão dissonantes, seja para aproximá-los, seja para começar a pensá-los a partir de outro viés que frutifique em práticas e medidas que viabilizem transformações positivas a serem usufruídas pelos Tribunais e, principalmente, pela sociedade.

81 A importância da atuação do Poder Judiciário e de suas instituições é indiscutível em um Estado Democrático de Direito. Nesse contexto, os Tribunais se configuram como um local de exercício e um espaço de concretização dos direitos de cidadania. Se não tem podido ser assim, é desejável que esse quadro se inverta. Nós vemos nas pesquisas de caráter empírico, em uma perspectiva comparativa, um importante instrumento para a criação de um campo crítico e reflexivo sobre o Direito e suas instituições, uma área de estudos jurídicos complementar, portanto, àquelas tradicionais, já capituladas pela pesquisa jurídica nas agências de fomento.

\section{BIBLIOGRAFIA}

AMORIM, Maria Stella de; LIMA, Roberto Kant de \& BURGOS, Marcelo Baumann (orgs). 2003. “A administração da violência cotidiana no Brasil: a experiência dos Juizados especiais Criminais". In: __-_ Juizados Especiais Criminais, Sistema Judicial e Sociedade no Brasil: ensaios interdisciplinares. Niterói: Intertexto. pp. 19-52.

AMORIM, Maria Stella de; LIMA, Roberto Kant de \& MENDES, Regina Lúcia Teixeira (orgs). 2005. "Introdução". In: ___. Ensaios sobre a igualdade jurídica: acesso à justiça criminal e direitos de cidadania no Brasil. Rio de Janeiro: Lumen Juris. p. xi-xxxviii.

BERMAN, Harold J. 2006. Direito e Revolução: a formação da tradição jurídica ocidental. São Leopoldo: Editora da Unisinos.

BOURDIEU, Pierre. 1968. “Campo Intelectual e Projeto Criador”. In: Problemas do Estruturalismo. Rio de Janeiro: Zahar Editores. pp. 105-143.

. 1987. "Sistemas de Ensino e Sistemas de Pensamento". In: A Economia das Trocas Simbólicas. São Paulo: Perspectiva. pp. 203-229. 
BOURDIEU, Pierre; CHAMBOREDON, Jean-Claude \& PASSERON, Jean-Claude. (orgs). 2004.

"Introdução". In: _--- (orgs.). Ofício de Sociólogo: metodologia da pesquisa na sociologia. Petrópolis:

Vozes. pp. 9-22.

CHIOVENDA, Giuseppe. 1938. "Procedimento Oral". Revista Forense, 74:41-64.

CUNHA BARRETO. 1938. "Oralidade e Concentração no Processo Civil”. Revista Forense, 74:65-76.

DAMATTA, Roberto. 1987. Relativizando: uma Introdução à Antropologia Social. Rio de Janeiro: Rocco.

DINIZ, Maria Helena. 1994. Compêndio de Introdução à Ciência do Direito. São Paulo: Saraiva.

EILBAUM, Lucía. 2008. Los 'casos de policia' en la Justicia Federal en Buenos Aires: el pez por la boca muere. Buenos Aires: Antropofagia.

. 2012. "O Bairro Fala". Conflitos, moralidades e justiça no conurbano bonaerense. São Paulo: Anpocs/Hucitec.

ESTELLITA, Guilherme. 1938. “O Processo Oral e sua Adoção no Brasil”. Revista Forense, 74:245-246.

FERREIRA, Marco Antonio Gonçalves. 2008. o Devido Processo Legal: um estudo comparado. Rio de Janeiro: Lumen Juris.

. 2013. A Presunção da Inocência e a Construção da verdade. Contrastes e confrontos em perspectiva comparada (Brasil e Canadá). Rio de Janeiro: Lumen Juris.

FIGUEIRA, Luiz Eduardo de Vasconcellos. 2005. Produção da Verdade nas Práticas Judiciárias Criminais Brasileiras: uma perspectiva antropológica de um processo criminal. Rio de Janeiro: Lumen Juris.

2008. O Ritual Judiciário do Tribunal do Júri. Porto Alegre: Sergio Antonio Fabris.

FOOTE-WHYTE, William. 1975. “Treinando a observação participante”. In: A. Zaluar (org.). Desvendando Máscaras Sociais. Rio de Janeiro: Livraria Francisco Alves Editora S.A. pp. 77-86. FOUCAULT, Michel. 2003. A verdade e as formas jurídicas. Rio de Janeiro: Nau.

FRAGALE FILHO, Roberto. 2006. "Ensinar Sociologia Jurídica nas Faculdades de Direito: possibilidades e significados". In: Roberto Fragale Filho \& Daniel Torres de Cerqueira (orgs.). 0 ensino jurídico em debate: o papel das disciplinas propedêuticas na formação jurídica. Campinas: Millennium Editora. pp. 45-58.

GARAPON, Antoine. 1997. Bem Julgar: ensaio sobre o ritual judiciário. Lisboa: Instituto Piaget.

GARAPON, Antoine \& PAPADOPOULOS, Ioannis. 2008. Julgar nos Estados Unidos e na França. Cultura jurídica francesa e common law em uma perspectiva comparada. Rio de Janeiro: Lumen Juris Editora. GEERTZ, Clifford. 1978. "O Impacto do Conceito de Cultura sobre o Conceito de Homem". In: A interpretação das culturas. Rio de Janeiro: Jorge Zahar. pp. 45-66.

. 1998. "O saber local: fatos e leis em uma perspectiva comparativa". In: o Saber Local. Petrópolis: Vozes. pp. 249-356.

GRECO, Leonardo. 2005. Estudos de Direito Processual. Campos dos Goytacazes: Editora Faculdade de Direito de Campos.

GUSMÃO, Sadi Cardoso de. 1938. “O Juiz no Processo Oral”. Revista Forense, 74:226-228.

HALL, Daniel E. 2009. Criminal Law and Procedure. Fifth edition. New York: Delmar Cengage Learning. 
KUHN, Thomas S. 2009. A estrutura das revoluções científicas. Tradução de Beatriz Vianna Boeira e Nelson Boeira. São Paulo: Perspectiva. pp. 175-183.

LEAL, Vitor Nunes. 1938. "Ignorância, rotina e chicana - os três maiores inimigos do Processo Oral". Revista Forense, 74:251-254.

LIMA, Roberto Kant de. 1995. A Polícia da Cidade do Rio de Janeiro: seus dilemas e paradoxos. Rio de Janeiro: Forense.

. 1997. A Antropologia da Academia: quando os índios somos nós. Niterói: EdUFF.

. 2008. "Por uma Antropologia do Direito no Brasil". In: ___. Ensaios de Antropologia e de Direito: acesso à justiça e processos institucionais de administração de conflitos e produção da verdade jurídica em uma perspectiva comparada. Rio de Janeiro: Lumens Juris. pp. 01-38.

2008a. “Tradição Inquisitorial no Brasil, da Colônia à República: da Devassa ao Inquérito Policial”. In: _-_. Ensaios de Antropologia e de Direito: acesso à justiça e processos institucionais de administração de conflitos e produção da verdade jurídica em uma perspectiva comparada. Rio de Janeiro: Lumens Juris. pp. 127-160.

. 2008b. "Prefácio". In: Bárbara Gomes Lupetti Baptista. Os Rituais Judiciários e o Princípio da Oralidade: construção da verdade no processo civil brasileiro. Porto Alegre: Sergio Antonio Fabris Editor. pp. 13-17.

. 2010. "Sensibilidades jurídicas, saber e poder: bases culturais de alguns aspectos do direito brasileiro em uma perspectiva comparada". Anuário Antropológico, 2009 (2):25-51.

LIMA, Roberto Kant de \& VARELLA, Alex. 2008. "Saber Jurídico e Direito à Diferença no Brasil: questões de teoria e método em uma perspectiva comparada”. In: Roberto Kant de Lima. Ensaios de Antropologia e de Direito: acesso à justiça e processos institucionais de administração de conflitos e produção da verdade jurídica em uma perspectiva comparada. Rio de Janeiro: Lumens Juris. pp. 89-126.

LUPETTI BAPTISTA, Bárbara Gomes. 2013. Paradoxos e ambiguidades da Imparcialidade Judicial: entre "quereres" e "poderes". Porto Alegre: Sergio Antonio Fabris Editor.

2008. Os Rituais Judiciários e o Princípio da Oralidade: construção da verdade no processo civil brasileiro. Porto Alegre: Sergio Antonio Fabris Editor.

MANNHEIM, Karl. 1974. “O problema da 'intelligentsia': um estudo de seu papel no passado e no presente”. In: ___. Sociologia da Cultura. São Paulo: Perspectiva. pp. 69-139.

MARINONI, Luiz Guilherme \& ARENHART, Sérgio Cruz. 2005. Manual do Processo de Conhecimento. São Paulo: Revista dos Tribunais.

MENDES, Regina Lucia Teixeira. 2012. Do Princípio do Livre Convencimento Motivado. Legislação, doutrina e interpretação de juízes brasileiros. Rio de Janeiro: Lumen Juris.

MENDONÇA, Meroveu. 1938. “O Processo Oral”. Revista Forense, 74:259-261.

MORATO, Francisco. 1938. “A Oralidade”. Revista Forense, 74:141-148.

MOREIRA LEITE, Ângela. 2003. Em Tempo de Conciliação. Niterói: Eduff.

MOTA, Fabio Reis. 2005. "O estado contra o estado: direitos, poder e conflitos no processo de produção da identidade 'quilombola' da Marambaia”. In: Roberto Kant de Lima (org.). Antropologia e Direitos Humanos 3 (Prêmio ABA/F. Ford). Niterói: Eduff. pp. 133-184;

OLIVEIRA, A. Gonçalves de. 1938. “Oralidade e Tradição”. Revista Forense, 74:93-95.

ROCHA PINTO, Gabriela Maria Hilu da. 2006. Os Caminhos do Leão. Niterói: Eduff. 
SANTOS, Moacyr Amaral. 1985. Primeiras Linhas de Direito Processual Civil. São Paulo: Saraiva.

SILVA, Robson Rodrigues da. 2011. Entre a caserna e a rua: o dilema do "Pato". Uma análise antropológica da instituição policial militar a partir da Academia de Polícia Militar D. João VI. Niterói: Eduff.

STRECK, Lenio. 2005. "A hermenêutica filosófica e as possibilidades de superação do positivismo pelo (neo) constitucionalismo". In: __-_. Constituição, sistemas sociais e hermenêutica: programa de pósgraduação em Direito da UNISINOS. Porto Alegre: Livraria do Advogado.

VELHO, Otávio. 1995. “Algumas considerações sobre o estado atual da antropologia no Brasil”. Revista Antropolítica, 1:103-113.

VIDAL, Paula Chagas Lessa. 2013. Os "Donos do Carimbo": Investigação Policial como Procedimento Escrito. Rio de Janeiro: Editora Lumen Juris.

\section{NOTAS}

1. Para efeitos deste artigo, deve-se fazer clara distinção entre "etnografia" e "trabalho de campo". É claro que o treinamento para o trabalho etnográfico requer longos períodos de pesquisa e sensibilidade treinada para observar e incorporar valores externos ao observador e relativizar os seus próprios. Já o trabalho de campo, mesmo realizado por pesquisadores em formação e não treinados especificamente para fazer etnografia, nesse caso, já introduz uma perspectiva de experiência inestimável na interpretação dos dados e na compreensão das instituições jurídicas e de seu funcionamento. Pela nossa experiência, é perfeitamente possível realizar pesquisas empíricas que se fundem em trabalho de campo, com entrevistas e observação direta e participante pelos operadores jurídicos, com excelentes resultados, mesmo sem que tenham sido configurados, em sua plenitude, os requisitos clássicos de uma etnografia tradicional.

2. Geertz, referindo-se à jurisprudence da common law, já reconhecia esse improdutivo distanciamento também em relação à Antropologia: "Sejam quais forem as outrascaracterísticas que a antropologia e a jurisprudência possam ter em comum - como, por exemplo, uma linguagem erudita meio incompreensível e uma certa aura de fantasia - ambos se entregam à tarefa artesanal de descobrir princípios gerais em fatos paroquiais [...] No entanto, essa sensibilidade pelo caso individual pode tanto dividir como unir [...] A interação de duas profissões tão voltadas para a prática, tão profundamente limitadas a universos específicos e tão fortemente dependentes de técnicas especiais teve como resultado mais ambivalência e hesitação que acomodação e síntese [...]" (Geertz, 1998:249).

3. "[...] a tradição viva e a consciência social subentendem responsabilidade. E responsabilidade significa excluir possibilidades e isso diz respeito a formas de escolhas entre muitos modos de pensar, perceber, classificar, ordenar e praticar uma ação sobre o real. Uma tradição viva é, pois, um conjunto de escolhas que necessariamente excluem formas de realizar tarefas e de classificar o mundo" (DaMatta, 1987:48).

4. Notícia veiculada no site do Superior Tribunal de Justiça, em 24/06/2009: "STJ e Enfam assinam acordos de cooperação técnica com universidades do Rio de Janeiro". Disponível em: http:// www.stj.gov.br/portal_stj/publicacao/engine.wsp?tmp.area=398\&tmp.texto=92591. Acesso em: $15 / 09 / 2013$

5. Edital disponível em: http://www.capes.gov.br/bolsas/programas-especiais/cnj-academico. Acesso em: 15/09/2013

6. Não confundir a lógica do contraditório com o princípio do contraditório. O princípio do contraditório é garantido na Constituição da República de 1988 (Brasil, 1988), em seu artigo 5: 
“Art. $5^{\circ}$ - Todos são iguais perante a lei, sem distinção de qualquer natureza, garantindo-se aos brasileiros e aos estrangeiros residentes no país a inviolabilidade do direito à vida, à liberdade, à igualdade, à segurança e à propriedade, nos termos seguintes: LV - aos litigantes, em processo judicial ou administrativo, e aos acusados em geral são assegurados o contraditório e ampla defesa, com os meios e recursos a ela inerentes".

7. Para mais detalhes sobre as formas tradicionais da disputatio e de suas posteriores transformações, ver Berman (2006). Tanto é assim que, mesmo no direito processual civil, supostamente disponível para as partes, porque discute questões de natureza privada, os artigos 348 e 350 do Código de Processo dispõem que a confissão faz prova contra o confitente e se caracteriza quando a parte admite um fato contrário ao seu interesse e favorável ao adversário, o que faz com que o trabalho do advogado seja "defensivo" e esteja voltado o tempo todo a se policiar para que não corra o risco de emitir qualquer declaração nos autos do processo que, em algum momento, possa vir a ser interpretada como uma possível "confissão" em prejuízo dos interesses de seu cliente.

8. Por exemplo: 1 . Notícia veiculada no site do $\mathrm{CNJ}$, sob o título "Em Manaus, presidente do CNJ afirma que o Judiciário quer alcançar o homemcarente de Justiça”. Disponível em: http:// www.cnj.jus.br/index.php?option=com_content\&view=article\&id=7891:em-manaus-ministro-

gilmar-mendes-afirma-que-o-judiciario-quer-alcancar-o-homem-carente-de-

justica\&catid=1:notas\&Itemid=675; 2 . Notícia veiculada no site do $\mathrm{CNJ}$, sob o título "Ministro Gilmar Mendes inaugura Casas de Cidadania para aproximar Judiciário da sociedade”. Disponível em: http://monoceros.cnj.gov.br/portalcnj/index.php? option=com_content\&view=article\&id=5392:ministro-gilmar-mendes-inaugura-casas-decidadania-para-aproximar-judiciario-da-sociedade-\&catid=1:notas\&Itemid=169; 3. Discurso do ex-presidente do STJ, ministro Raphael de Barros, em 2007: "O estreitamento dos laços entre a Justiça e a sociedade civil é um excelente caminho para agregar valores capazes de elevar os jurisdicionados à vivência da real cidadania e da plenitude da dignidade humana". Disponível em: http://www.stj.gov.br/portal_stj/publicacao/engine.wsp?tmp.area=398\&tmp.texto=85744.

Acesso em: 15/09/2013

9. A categoria "manualização" costuma ser apropriada por aqueles que, como nós, pretendem evidenciar uma crítica à forma reprodutiva como o Direito se estrutura enquanto campo do conhecimento. Oscar Vilhena, em certa ocasião, referindo-se à sua formação mesclada entre o Direito e as Ciências Sociais, disse que, ao ingressar nos referidos cursos, viu-se entre "o deserto manualesco dos juristas e a sedutora literatura das demais ciências humanas" (Entrevista disponível em: virtualbib.fgv.br. "Os livros que fizeram minha cabeça"). Lenio Streck (2005:180), em seu texto "A hermenêutica filosófica e as possibilidades de superação do positivismo pelo (neo) constitucionalismo", refere-se a "uma cultura positivista e manualesca que continua enraizada nas escolas de direito e naquilo que se entende por doutrina e aplicação do direito". João Maurício Adeodato também usa a expressão na orelha de seu livro O Direito Dogmático Periférico e sua Retórica, ao mencionar que o livro "procura fugir ao caráter manualesco que tem caracterizado boa parte da produção jurídica nacional".

10. A expressão dogmática equivale à doutrina jurídica que, no Direito, significa: "o estudo de caráter científico que os juristas realizam a respeito do direito, seja com o objetivo meramente especulativo de conhecimento e sistematização, seja com o escopo prático de interpretar as normas jurídicas para sua exata aplicação" (Diniz, 1994:284). Na verdade, em síntese, pode-se dizer que a dogmática é um normativismo inspirado na teoria positivista Hans Kelsen.

11. Em outro trabalho sobre o tema, de menção oportuna, define-se melhor o conceito de etnografia: “o ponto central do método etnográfico é a descrição detalhada e a interpretação dos fenômenos observados com a indispensável explicitação tanto das categorias 'nativas' como aquelas do saber antropológico utilizado pelo pesquisador [...]" (Lima, 2008:12). Para entender como fazer etnografia, utilizando-se da observação participante, ver Foote-Whyte (1975). 
12. Otávio Velho fornece uma definição interessante para quem não é do campo das ciências sociais acerca da metodologia antropológica: “[...] Antropologia não tem 'métodos e técnicas', antropologia é uma coisa que entra pelos poros, uma coisa espontânea, uma coisa que tem a ver com esse grande contato fundamental com o campo ou com os nossos interlocutores, ou, enfim, com o grupo social que estamos estudando" (1995:106).

13. Na mesma linha, Roberto Fragale discute a importância de uma visão sociológica para a compreensão do Direito (Fragale Filho, 2007).

14. Notícia do Superior Tribunal de Justiça, divulgada em 11/05/2005, intitulada: "Ministro Vidigal diz em Fortaleza que desconhece pesquisa do STF". Disponível no site oficial do STJ: www.stj.jus.br.

15. Fragale Filho, tratando da importância da sociologia jurídica para refletir e repensar o Direito, manifesta-se nessa mesma linha, destacando-se (Fragale Filho, 2007:55-56): “[...] a sociologia jurídica pode ser uma fundamental alavanca [para desnaturalizar as certezas produzidas pelo direito], na medida em que ela impulsione a adoção de uma postura 'epistemológica' que lance a semente da dúvida, que elimine os obstáculos de uma discussão mais aberta e questionadora [...] Ensinar (e aprender) sociologia jurídica nasfaculdades de direito é uma necessidade para desmistificar certezas e explicar que o mundo é muito mais complexo e inseguro do que sugere a certeza da norma, é uma necessidade para explicitar como o mundo do direito é fruto de construções circunstanciais e cambiantes. Embora seja tão difícil viver sem as aparentes e ingênuas certezas do direito, seria uma pena se esquecêssemos que, entre os extremos do negro e do branco, há inúmeras tonalidades de cinza".

16. A respeito da desarmonia entre a teoria e as práticas judiciárias, ver Garapon (1997) e Garapon e Papadopoulos (2008). Garapon destaca que a sacralização da lei desqualifica a prática jurídica e questiona o fato de o Direito exigir a aplicação de regras que visam a um ideal. Ele ressalta que "um direito demasiado ideal é muitas vezes inaplicável", de modo tal que "o distanciamento entre o direito dos livros e o direito vivido tornou-se perigoso", tendo em vista que, para ele, a distorção entre o que a lei determina e o que a prática realiza causa uma "anomia" decorrente não da ausência do Direito, mas do seu "caráter demasiado abstrato" (Garapon, 1997:180). "O direito visa a fazer com que o mundo dos fatos esteja em conformidade com um mundo ideal; a transformar o mundo tal como ele é em um mundo tal como deveria ser" (Supiot, 1994 apud Garapon, 2008:42).

17. Nesse sentido, como destacado acima, a preocupação dos “doutrinadores" em legitimar o seu saber, fora do contexto acadêmico, torna-se maior do que o compromisso com o conteúdo daquilo que sustentam, privilegiando o argumento de autoridade em detrimento da autoridade do argumento, o que acaba, muitas vezes, restringindo o conhecimento jurídico ao contraditório de opiniões, inspirado na tradição da disputatio da escolástica medieval (Berman, 2006:163-167).

18. Voto proferido pelo ministro Humberto Gomes de Barros nos autos do agravo regimental nos embargos de divergência em recurso especial (AgReg em ERESP) nº 279.889/AL. Disponível em: https://ww2.stj.gov.br/revistaeletronica/ita.asp?

registro=200101540593\&dt_publicacao=07/04/2003. Acesso em: 15/09/2013

19. Lima (1995:6), ao descrever as suas dificuldades de adaptação ao universo jurídico, menciona exatamente o aspecto da relativização, destacando que o seu embate se deu, especialmente, por causa da "impossibilidade de relativização explícita dos valores implícitos na prática advocatícia".

20. Art. 5o, inciso LXXVIII, CRFB/88: “a todos, no âmbito judicial e administrativo, são assegurados a razoável duração do processo e os meios que garantam a celeridade de sua tramitação".

21. A leitura de Berman (2006) ajuda-nos a compreender que é na universidade que se firmam os cânones metodológicos do saber científico. Do mesmo modo, Bourdieu (1987) trata deste assunto quando menciona no texto em que discute os sistemas de ensino e sistemas de pensamento que 
“[...] quanto mais tais esquemas [de pensamento] encontram-se interiorizados e dominados, tanto mais escapam quase que totalmente às tomadas de consciência [...]”.

\section{RESUMOS}

A importância de articular Direito e Antropologia - embora reconhecida por instituições como o MEC, que inseriu a Antropologia Jurídica no currículo da graduação em Direito, e pelo CNPq, que a elenca como subárea do Direito - ainda não está de fato legitimada pelos operadores jurídicos. 0 fazer antropológico pressupõe a relativização de verdades consagradas, enquanto o fazer jurídico através delas se reproduz, sendo este contraste metodológico um significativo obstáculo ao diálogo destes campos. Exercitar a aproximação destes saberes é um desafio não apenas para o Direito, mas também para a Antropologia, pois ambas as áreas não pautam as suas agendas a partir de discussões comuns. Este artigo destaca a importância de uma metodologia própria da antropologia, a etnografia, de base empírica e calcada no trabalho de campo e na perspectiva comparativa contrastiva, para o desenvolvimento da pesquisa na área do Direito. Demonstraremos que essa metodologia é extremamente valiosa para a compreensão do campo jurídico, como também explicitaremos alguns dos obstáculos que causam os ruídos de comunicação desses campos. A metodologia utilizada para a construção dos dados é fruto da observação participante dos autores, que são formados em Direito e têm experiência acadêmica e profissional na área da Antropologia Jurídica.

In Brazil, Law and Anthropology are very separate fields of knowledge. This is due not only to their particular characteristics as fields of knowledge - law being quite instrumental directed to solve problems, anthropology quite reflexive, directed to ask questions on comparative matters but also due to the methods that both use to produce and legitimately reproduce their knowledge. As a social science, Anthropology is an empirical science based on comparative fieldwork experiences; besides that, Anthropology builds scientific evidence based on temporary consensus on facts; Law is a normative and abstract field of knowledge, which uses a particular truth finding adversarial method, called "contraditório", which consists in an infinite dispute between the involved parties, who cannot agree over evidence; such a dispute can only be terminated by a third party with authority. As such, Brazilian law refuses to legitimate evidence and legitimates only knowledge produced by an authority: its knowledge is abstract and normative and its reproduction does not stimulate reflection and creativity. Empirical research on Law, conducted either by Law agents or by social scientists, may help shed light upon legal practices and their meanings, contributing to a more productive dialogue between these two fields of knowledge.

\section{ÍNDICE}

Keywords: legal anthropology, comparative method, fieldwork and ethnography in the field of law

Palavras-chave: antropologia jurídica, método comparativo, pesquisa empírica e Direito, etnografia jurídica 


\section{AUTORES}

\section{ROBERTO KANT DE LIMA}

UFF. Roberto Kant de Lima é coordenador do INCT-InEAC - Instituto de Estudos Comparados em Administração Institucional de Conflitos, e do Núcleo de Ensino, Pesquisa e Extensão em Administração Institucional de Conflitos - NEPEAC/PROPPI/UFF; pesquisador de Produtividade 1A do CNPq e Cientista do Nosso estado/FAPERJ; professor do Departamento de Segurança Pública da Faculdade de Direito da UFF e dos Programas de Pós-Graduação em Antropologia e Direito Constitucional da UFF. Contato: rkantbr@gmail.com

\section{BÁRBARA GOMES LUPETTI BAPTISTA}

UCP. Bárbara Gomes Lupetti Baptista é pesquisadora do InEAC, Professora permanente do Mestrado em Direito da Universidade Católica de Petrópolis - PPGD/UCP e da Faculdade de Direito da UFF e Advogada. Contato: blupetti@globo.com 